\title{
Research on the Conflicts of the Tracking System in Township Junior High Schools in Jiangxi from the Perspective of the Environment of Compulsory Education
}

\author{
Zhiwen Yang \\ Business School of Jiangxi Institute of Fashion Technology \\ Nanchang, Jiangxi, China
}

\author{
Pingzhen Zhou \\ Design School of Jiangxi Institute of Fashion Technology \\ Nanchang, Jiangxi, China
}

\begin{abstract}
In China a large number of parents have the same belief in their children's education; that is 'Don't let them lose at the starting line". They regard the kindergarten as the first starting line for their children and the stage of primary school learning as a second starting line. And What's more, they believe the process of entering senior high school from junior high school is the most important staring line for all the children. On the one hand, the Compulsory Education Law in China bans the tracking practice of separating students into different groups according to their ability in junior high schools below the county level. On the other hand, the tracking teaching practice is very common and popular among all the junior high schools below the county level for several reasons. First, it is demanded by the parents because they want their children to study with those hard-working students together. If the schools don't do so, they will lose a lot of top students in academic studies as they don't want to be disturbed by the underachievers. The enrolment rates of the schools will also be severely reduced. The tracking system in junior high schools will retain some of the outstanding students. Meanwhile, high enrolment rates will also bring good reputation to the school. However, due to the tracking system, the developments of the students in the ordinary classes have been largely influenced at an early age because of inferior learning environment, teachers, and management and personal foundations. How can we change that? Under the environment of compulsory education system, how can the students in township junior high schools be well educated in different levels? How to make every student become a useful person in the society in the future? This is the key question to be discussed in this paper.
\end{abstract}

Keywords - compulsory education, township junior high school, the tracking teaching system

\section{BACKGROUND AND THE STATUS QUO}

In China, There are many criteria for the research of compulsory education law, and there are many problems existing in the research. There is almost no study which is against the compulsory education. The Compulsory Education Law was promulgated in April 1986 and revised in 2006, and now it has been relatively mature. The Compulsory Education Law of our country has played a guiding role in the compulsory education stage.
Along with the development of China's urbanization, some children whose households are originally registered in towns and villages are now living and studying in the county and urban areas with their parents and the children's schooling has become a very worrying problem for most parents living in the countryside. Parents who have the ability and foresight would love to do everything they can to get their kids to study in the county or urban middle schools, so the house prices in the vicinity of the key schools have been rising recently. One of the influences is that the size of the classes in county junior high schools is becoming bigger and bigger; some are even over 80 people in one single class. On the contrary, the students in the villages and towns and rural junior high schools are becoming fewer and fewer. Under such circumstances, in order to obtain good reputation and keep good students, and to cater to the demand of some parents (some parents even clearly expressed their opinion to the school leaders that they would transfer their children to a different school if tracking system was not implemented in the school), some of the schools in the villages and towns have no choice but to divide the students into different classes according to their ability in academic studies. Some schools even track their students into different levels the first year they come to junior high school by asking them to sit certain tests. Outstanding teachers and materials will be equipped to the class of top students as likely as possible. Then the enrolment rate of the school will be higher and it can also get good reputation. However, the worst part about it is that the prospects and development of the students in the regular classes will be destroyed in this way due to inferior learning environment. For the students who didn't get good grades in elementary school for reasons of themselves or from their family, they will face a really bad learning environment even they want to study harder in junior high school. It is also the same for those students whose foundation is poor and those who didn't perform properly and didn't get good grades due to some reasons in the exams.

Under the environment of exam-oriented education, on the one hand, the education law does not allow the schools to divide the students into different levels of classes in township junior high schools under county level. Meanwhile, the education administrators above the county level have also expressed clearly the regulations of not allowing tracking 
teaching system in the schools. However, many schools just disobey the above regulations for their own interests, but also to meet the needs of some parents and students. Cry up wine and sell vinegar. This is the current situation for many township junior middle schools in Jiangxi.

\section{CAUSES FOR THE CONFLICTS IN THE TRACKING SYSTEM}

Each parent is on the tiptoe of expectation on his kid to become an outstanding person in the future. A county may have only one or two excellent high schools and teaching software and hardware facilities are all limited, and excellent teachers are limited, too. So it is not possible for every student to study in a good high school. In fact, students in the regular classes in township junior high schools can hardly get a good education. High quality teachers are rarely matched to the regular classes. One of the reasons is that the teachers have been severely exposed by the media in recent years. First, the teacher cannot practice physical punishment to students. Second, they can't beat or scold students. Third, the teacher shall not fight with students. Another reason is that the quality of the student in regular classes is relatively poor and they do not respect teachers; as a result, many teachers don't want to teach them and also many students do not have the motivation to learn either. Therefore, the students perform really badly and many bad habits will occur in the class, such as showing no respect to the teachers, no discipline, talking in class loudly, walking around in the class without permission, etc. Controlling the students in regular classes has become a big challenge in many schools and this has also become a concern for the development of the society.

Of course, most of these children are left-behind children whose parents are migrant workers working in a different place. So they cannot teach their children themselves. In addition, some parents cannot teach their children due to lack of knowledge. They completely pin their hopes on school education. And for the teachers who teach students in the regular classes are not satisfied with the unfair salary distribution system according to performance (for example, middle or top leaders get rich performance wages, and the teachers teaching senior entrance exam course will get 1 score for teaching one lesson and the teachers who teach music, information technology, etc., only get $85 \%$ - $90 \%$ of the other teachers' salary for each class). The teachers' salaries are quite low. The quality of the students is relatively poor and the teachers can't beat or scold students, so whether they are responsible or are not, they just get the same salary. The less trouble the better, so many teachers just do not want to manage those students with bad behaviors in class, and many teachers have become a security guard. As long as there is no trouble, everything doesn't matter to him.

In a broader sense, if a country wants to develop, education is the foundation. Whether a country can become more and more prosperous basically depends on the education of the next generation. If the next generation's education is not good, it will bring direct impact on the country's prosperity or decline.

When it comes to the university entrance exam, now the education in China is still exam-oriented education, students are forced to learn the same subjects whether you like them or not. The school is not teaching students according to their interests. Each student's life planning is based on the national education planning. It is just cramming teaching, and it is hard to cultivate the needed talents to adapt to the different stages and needs of the society. In the past, the majority of rural students were willing to study, mainly because they could go to cities to live if they studied well and went to college in the city. Then they could find a job that was enviable and had a fixed salary, and even make themselves, their parents even their children live better. Nowadays, the quality people's lives has been improved largely, so many students do not need to worry about their living conditions as their parents will provide everything to them and treat them as the apple in their eyes. In the present society, many people who have not studied well are living better than those who have gotten higher degrees from college, which causes some students to have less enthusiasm to study. If they study in the regular class, they are less willing to learn, because they can't pass the exam to go to a good university or college. So they just give up the learning spirit in school.

When it comes to good students, they learn in class, because the good learning environment, excellent teachers and strict management, it is becoming easy for the good students to go to a very good high school. If a student is already in high school, it will increase the students self-confidence, and the students will have honor, too. Once they are in a good high school, it is equivalent to entering the university. If students study hard themselves, the chance to study in a very good university will increase a lot.

When it comes to the Bureau of education, though they forbid schools to select outstanding students and prohibits the junior high schools to divide students into different levels of classes, almost all the township junior high schools are practicing the tracking system except a few schools in the county. On the surface it is no difference in each class, but education leaders, school leaders, teachers and parents know their every child's identity.

Why are these school leaders taking risks? This is social and parents force. If they do not divide the students into different levels of classes, the school's enrolment rate to high school will be lower and the parents are not satisfied, either, even the teachers are not satisfied. All this will affect the school's reputation. Further, that will affect the school's enrollment of new students next year.

\section{IMPROVEMENT MEASURES}

\section{A. We should take classification tests. Do not select students only according to their scores.}

When students go to junior high school to study, a good education program should be tailored to the students' own conditions. Students select the class according to their interests, specialties and wishes, and accept the learning or skill of the corresponding system. The university entrance exam should also be adjusted, according to the national development plan and education planning. Do not select the talents only according to the scores. In order to meet this requirement, not only the education leaders should have the macro thinking and 
decision-making abilities, but the schools cannot be allowed to be divided into different levels of classes according to just one test result. Regular education students should selectively enter the craft class, music, dance, sports class to learn according to their interests, the needs of the society and the students' actual situation. So different classes of students will be able to go to different colleges and universities or higher vocational schools to further their study according to their academic performance. Thus, each one would have achieved their dreams and would become a useful person for the society.

But now under the influence of traditional concepts, the Chinese people generally do not recognize the higher vocational education, and they always feel vocational colleges are inferior to others. So the new college entrance examination of classification tests did not cause enough echo. Neither did it play a proper role. If the new college entrance examinations do not be treated as the only criteria to select talents and break the old selecting system of scores only. As it obviously lead to China's low rate of elites with so big a population. If they can carry out the reform, the school will be full of vitality and each student will be able to find their own interests by implementing classification learning and classification of the exams. Then the students can finally become useful persons of the society when they grow up.

\section{B. The school should pay attention to the cultivation of students' interests and specialties.}

Parents know their children quite well, so they should help their children to make proper life planning. They should help their children to choose the best professional directions when they are still in childhood to ensure that they can grow healthily, become a talented person and to achieve success for them to the greatest extent. Each family should try to help the students to find their own interests, specialty and hobbies from an early age, and they all needs continuous discovery, guidance and training. Primary school is the starting point, and the junior high school stage is an important milestone. It should be done in a few counties and cities to check the effect, and then it can be fully implemented all over the whole country. China's college entrance examination system should be changed accordingly.

\section{The traditional exam-oriented education model should be phased out gradually.}

As is known to all, China's exam-oriented education has been in practice for decades, and it has formed the complex community of interests. It also has caused many training and counseling agencies to be set up. It also formed a strong and stubborn exam-oriented education love knot in the hearts of several generations in China. The whole society is filled with the exam-oriented education idea, and its power is still solid. To reform innovation, we must make up our minds to go from the highest level of the central government. We will carry out major changes from the primary school entrance exams to the college entrance examination and we believe that even the biggest struggle will not shake the general direction of change. Professor Mingyuan Gu once pointed out that in the future, the college entrance examination system will be thoroughly reformed, and the model of examination-oriented education will definitely be eliminated in the future. It is useful to change the "examination-oriented education" thoroughly. Although the process of change may be long, especially the transformation of ideas.

\section{China's education system "can't wait" for innovative talents.}

The university entrance exam has been restored for 40 years and the policy of reform and opening-up to the outer side world has also been 40 years now. In the past, various aspects in China's were terribly short of talents. So China's education needs to "copy" a large number of talents for 40 years, and this kind of talent education training mechanism has played an important role for China's economic growth.

As the consumption of natural resources continues to intensify and the environmental pollution is becoming deeper and the GDP is falling rapidly, the most urgent need in China is innovation. Innovation is to be innovated by innovative talents, and the training of innovative talents requires the system and mechanism of suitable education.

Innovative talents of major developed countries in Europe and the United States, are much greater in numbers than our country. The exam-oriented education is a closed education, and the closed education is difficult to form an open environment. It is difficult to produce a large number of innovative talents. Therefore, the great changes in China's education are urgent.

\section{E. We should increase education and life planning for students.}

The comprehensive quality education content is very complex and the system is numerous, as it is not like a single exam-oriented education. So it needs to be scientific and reasonable, and it needs a very objective and comprehensive grasp and strategy.

"Professor Ming-yuan Gu also pointed out in this regard. He said that career education mainly tells children how to know yourself, how to understand others, know their own advantages and disadvantages. So let them have a comprehensive understanding of themselves so as to plan their future learning and life in advance.

If comprehensive quality education does not plan for each student's career education, it is easy to deviate from the direction.

\section{SUMMARY AND PROSPECTS}

The rural and township junior high schools in Jiangxi change the old teaching system and introduce innovative classification study practice according to the opinions of the parents, the development needs of the school, the needs of the social change, the students' interest and life planning is the complement to and development of the compulsory education. At the same time, it will also point out the reference direction for the education of the next generation for our whole country. This system can take care of the various levels of students, and encourage every student to realize their own dreams and become a useful person in the society. 


\section{REFERENCES}

[1] "Actively Promoting Balanced Development of Compulsory Education, and Further Promoting Educational Equity and Fairness - the Ministry of Education Issued a Further Guidance on the Balanced Development of Compulsory Education", Petroleum Education, P.94., 03, 2005.

[2] Zhang Junfeng, Wang Yinfei, "Equal Allocation of Compulsory Education Funds" - Also on the "County Oriented" Rural Compulsory Education Funding System”. Basic Education Reference, PP.33-34, 01, 2005.
[3] Ji Han, "Effect of Tax Reform on Rural Compulsory Education". Accounting Monthly, PP.31-32, 10, 2005.

[4] Yang Huaxiang, Zhang Yu, “Analysis of Rural Education in Wuhan”. "Analysis and Prediction of Economic and Social Situation in Wuhan." Wuhan Publishing House, PP.382-394, March 2005, first edition.

[5] Lu Yuan, "The Problems and Countermeasures in the Teaching Management of Rural Junior Middle Schools”. The Course Teaching Research; Pedagogy Teaching Research, PP. 202,3, 2017. 